\title{
Use of Solid Dispersions and Inclusion Complexation for Enhancing Oral Bioavailability of Ziprasidone in Treating Schizophrenia
}

\author{
Poonam Mogal", Deeliprao Derle \\ Department of Pharmaceutics, M. V. P. S' College of Pharmacy, Nashik, India \\ Email address: \\ poonammogal@gmail.com (P. Mogal) \\ ${ }^{*}$ Corresponding author
}

To cite this article:

Poonam Mogal, Deeliprao Derle. Use of Solid Dispersions and Inclusion Complexation for Enhancing Oral Bioavailability of Ziprasidone in Treating Schizophrenia. Journal of Drug Design and Medicinal Chemistry. Vol. 3, No. 3, 2017, pp. 37-48. doi: $10.11648 /$ j.jddmc.20170303.12

Received: May 19, 2017; Accepted: June 21, 2017; Published: July 25, 2017

\begin{abstract}
In modern times, people are suffering from many mental health disorders like schizophrenia, bipolar disorders and many psychoses. Hence, it is essential to treat these mental disorders using medications as well as with assistance from caregivers for the social well being of person. This study was focussed on improving solubility \& dissolution of poorly soluble drug Ziprasidone using different formulation approaches like solid dispersion \& inclusion complexation. Different solubility enhancing techniques like physical mixing, solvent evaporation, microwave irradiation, lyophilization \& spray drying were used for the along with four different polymers i.e Kollidon, Soluplus, Pluronic and HP $\beta C D$. The prepared formulations were evaluated for saturated solubility, dissolution, ATR, SEM, XRD, pharmacodynamic and pharmacokinetic in vivo study. The prepare formulations showed increment in solubility as well as dissolution. The order of solubility enhancement for the studied polymers was found to be of following order: Soluplus $>\mathrm{HP} \beta C D>$ Kollidon $>$ Pluronic. In the pharmacodynamic study, the optimized solid dispersion showed the calming effect on mice when compared to pure Ziprasidone. The pharmacokinetic study demonstrated the increase in oral absorption of Ziprasidone in all prepared formulations and it followed the same order as that solubility \& dissolution enhancement. The Soluplus-solid dispersion prepared by spray drying technique was found to be suitable in enhancing oral absorption with significant $(\mathrm{p}<0.05)$ enhancement in Cmax \& AUC than pure Ziprasidone. Hence, comparative study was helpful in increasing oral bioavailability Of Ziprasidone in choosing the suitable polymer with decreasing the dose and increasing patient adherence to therapy.
\end{abstract}

Keywords: Ziprasidone, Solubility, Kollidon, Soluplus, Pluronic, HP $\beta C D$, Solid Dispersion

\section{Introduction}

Recently, World health organization's (WHO) 66th World Health Assembly has supported "Mental Health Action Plan 2013-2020" which is very essential for the social well being of people suffering from mental disorders like schizophrenia, bipolar disorders, depression etc. in the world. The formal step taken by WHO representing the need of addressing the mental health disorders faced by today's world $[1,2]$. Mental ill health is the leading cause of concern in the modern period of time because it is affecting health, social wellbeing of a person, human rights \& imparting high economical load on the patient's family [3-5]. There are many Mental health disorders that world is facing like depression, bipolar disorder, schizophrenia \& other psychoses, dementia, cognitive disabilities as well as developmental disorders like autism.

Schizophrenia is a mental disorder affecting severely, defined by intense disturbance in thinking, language, emotion, basic cognitive process \& consciousness. It involves psychotic experiences, like hearing voices or delusions. Thus, it is affecting performances at various social and work levels. According to WHO "Schizophrenia is a severe mental disorder affecting more than 21 million people worldwide." it is also posing lot of expenditure cost i.e. direct treatment cost as well as non-healthcare cost like difficulties in earnings, poor performance at work etc. But, 
Schizophrenia can be treated with medication and assistance of family members or caregivers [6].Schizophrenic psychosis need long care, even though symptoms have lessened. For psychotic disorders the effective management of signs \& symptoms is essential with low dose. The $2^{\text {nd }}$ generation antipsychotic drugs have fewer side effects hence are safer to use. Injectables suffers from disadvantages like "slow dose titration", longer time needed for reaching steady state, topical side effect, frequent visits to clinics [7-11]. Also, they are invasive which refrain patients from adhering to the treatment which is main area of concern as it usually leads to relapsing, morbidity, mortality \& giving lot of economical burden to families [12].

Ziprasidone has affinity towards receptors (from highest to lowest) like 5-HT2A, 5-HT1A, D2, $\alpha 1$, D2 [13]. Millions of peoples are suffering from schizophrenia \& other psychosis every year. Ziprasidone is binding to receptors such as D2, D3, 5HT1A, 5HT2A, 5HT2C, 5HT1D in nano molar affinity. \& possibly acts as antagonist to D2 \& 5HT2A receptors [14]. Ziprasidone is undergoing various clinical trials for Schizophrenia, Schizoaffective Disorder, Bipolar Depression, Social Anxiety Disorder \& also as monotherapy for Major Depressive Disorder, Generalized Anxiety Disorder, Disorders with Psychotic Features, Autism, Major Depressive Episode, Affective Psychosis, Mania, Manic-Depressive Psychosis, Delusional Disorder, Acute Exacerbation of Psychosis, Posttraumatic Stress Disorder, Disruptive Behaviour Disorders [15].

Ziprasidone (ZP) (Melting range: $\approx 300^{\circ} \mathrm{C}$ ) of BCS class II is an effective orally active atypical antipsychotic drug and belongs to the indole derivatives group with poorly watersoluble characteristic and poor oral bioavailability $59 \%$ (oral). It undergoes extensive metabolism by metabolizing enzymes like aldehyde oxidase $(66 \%)$ \& CYP3A4. Ziprasidone also undergoes high $(99 \%)$ plasma protein binding. It is chlorooxyindole class aryl-heterocyclic which is used to treat mental health disorders such as schizophrenia and bipolar disorder [16-22]. After getting approval affirmed in 2001, Ziprasidone is accessible as an oral suspension, capsule \& intramuscular injection, selling worldwide under the names of Geodon ${ }^{\circledR}$ or Zeldox ${ }^{\circledR}$. Ziprasidone, after lot of work \& clinical studies, is found to be safe [23-25], efficacious [26, 27] $\&$ cost-viable [28-30]. Its oral bioavailability is enhanced almost 2 times when taken with food [31]. Notwithstanding, consistence can be a noteworthy issue in patients with schizophrenia to the endorsed treatment [32].

Various advancements are accessible for enhancing the solvency or dissolution of a poorly soluble drug, for example, prodrug [33], co-crystal [34], lipid frameworks [35], SNEDDS [36], complexation (inclusion) [37], amorphous [38], what's more, molecule size diminishment in nanomilling [39]. The literature data indicate that many studies are carried out for solubility enhancement of Ziprasidone focussing on utilization of various derivatives of cylodextrins [40, 41]. It has been shown that different salt forms of Ziprasidone have different solubility due to the degree of ion pair formation between ziprasidone \& the counterion [42].

Ziprasidone has been explored as fast dissolving tablets, solid nanocrystalline dispersion, and nano suspensions [43, 44]. A novel solubilized drug form i.e. coated crystals made by spray drying (CCSD), was prepared \& pharmacoscintigraphy study was used later for human clinical studies [45]. Ziprasidoneis having pka of 6 hence solubility decreases with increase in $\mathrm{pH}$ [46]. In deodenum, it is having modest absorption as reported [47]. The Ziprasidone-SNEDDS sustained-release pellets were also studied by using extrusion-spheronization to enhance the oral bioavailability and overcome the food effect of Ziprasidone [48]. The advanced formulation approach was also tried like lipid-based drug delivery systems (LBDDS) for oral administration of Ziprasidone [49]. The amorphization \& other difficulties during the development of formulations containing amorphous Ziprasidone, prepared by grinding in high-energy planetary ball mills or cryogenic mills were studied for Hcl salt [50].

Much attention is also given for the development of ziprasidone mesylate salt and its intramuscular administration. However, very little data is available regarding the use of ziprasidone Hcl salt as well as its oral administration. In addition to this, there is lack of information regarding use of various hydrophilic polymers for the solubility enhancement of Ziprasidone with its in vivo data. It was noted that very few studies are available that uses the different polymers as well as different solubility enhancing technique for model drug in same lab setting which is essential for meaningful comparison and to get reliable data for particular drug or technique utilized for it. Thus, this study was focussed on the use of various hydrophiles using different solubilizing techniques giving comparative data for complete understanding of the solubility improvement for Ziprasidone.as well as directs regarding the best suited carrier or solubility enhancing technique to be utilized for the formulation.

\section{Materials and Methods}

\subsection{Materials}

Ziprasidone $\mathrm{Hcl}$ (ZP) was obtained as gift sample from Wockhardt, Aurangabad, India. Hydroxypropyl beta cyclodextrin (HP $\beta C D)$ was obtained as gift sample from Glenmark pharmaceuticals, Sinnar, Nashik, India. Poloxamer (Pluronic F-127) (PO) (Sigma aldrich) whereas Soluplus (SO), Kollidon VA 64 (KO) were obtained as gift sample from BASF, Turbhe, India. All other reagents \& chemicals used were of analytical grade.

\subsection{Methods}

\subsubsection{Preparation of Formulations: Physical Mixtures (PM) and Kneading (KD)}

Physical mixtures, in different ratios $(1: 1,1: 2,1: 3)$ were prepared by mixing Ziprasidone with polymer for four to five min in a mortar till a uniform mixture was acquired. The 
mixtures obtained were passed through sieve (100 $\mu \mathrm{m}$ mesh) after which they were stored in a desiccator at normal temperature for further usage. Whereas for kneading, small quantity of solvent was added as well as both drug-polymer mix were kneaded together and solvent was evaporated further to get dry mass.

\subsubsection{Solvent Evaporation Method (SE)}

Binary systems in various ratios like $(1: 1,1: 2,1: 3)$ were made by dissolving Ziprasidone in Nonaqueous solvent whereas, polymer was made soluble in aqueous solvent. Dissolved drug solution was add together to hydrophilic water solution by constant stirring and add-on rate of 7-9 $\mathrm{ml} / \mathrm{min}$. Nonaqueous phase was evaporated in oven at $45-$ $50^{\circ} \mathrm{C}$. The product obtained was passed through sieve No. 100 and then stored in desiccator at room temperature till further analysis by UV.

\subsubsection{Lyophilization (LY)}

The Ziprasidone and polymer $(1: 1,1: 2$, and 1:3) were accurately weighed when Ziprasidone (ZP) was made soluble in methanol \& polymer in aqueous solution. Methanolic solution was added up to water solution by uninterrupted stirring at the rate of $5-6 \mathrm{ml} / \mathrm{min}$. The nonacqueous solution (methanol) was removed by evaporation at room temperature. It was later lyophilised in Labconco lyophilizer (USA) after initial freezing with vacuum 0.040 mbar. The lyophilised product thus obtained was stored in dessicator at room temperature.

\subsubsection{Microwave Irradiation Method (MW)}

The Ziprasidone and polymer $(1: 1,1: 2$, and 1:3) were accurately weighed. A homogeneous paste was made by adding Ziprasidone and polymer with minimal quantity of solvents (Ethyl alcohol: H2O, 1:1 v/v) inside vessel. The paste developed was subjected to microwave irradiation for 7-8 min at power of 510 watt in a microwave (oven) synthesizer (CATA-R, catalyst systems, Pune, India). Just a single beaker was set at once inside the microwave synthesizer. The specimens were presented to microwave radiation for 7-8 min. at that point, the beakers containing tests were kept up at normal temperatures to cool down. The formulations were gathered and put in desiccator for 24 hours and afterward the item was powdered utilizing mortar and pestle. The powdered product was sieved through sifter no. 100 and put away in desiccators over combined calcium chloride.

\subsubsection{Spray Drying (SY)}

Each solution for spray drying was prepared by adding different ratio of Ziprasidone and polymer (1:1, 1:2, 1:3) to $200 \mathrm{ml}$ of methanol. It was exposed to ultrasonication by a bath sonicator for about $10 \mathrm{~min}$. After that spray drying was carried out in a lab spray dryer model LU-222 Advanced (Labultima, Mumbai, India) with the drying capacity of 1 $\mathrm{L} / \mathrm{h}$. Parameters set for spray drying were like using $4 \mathrm{ml} / \mathrm{min}$ flow rate, $80^{\circ} \mathrm{C}$ of inlet temperature, with $60-70^{\circ} \mathrm{C}$ of outlet temperature, and aspirator value of about $60 \mathrm{~m}^{3} / \mathrm{h}$.

\subsection{Attenuated Total Reflectance Spectroscopy (ATR) Analysis}

Supporting evidence for formation of solid dispersion can be obtained by IR spectroscopy. Attenuated Total Reflectance spectra of the drug samples were obtained on a Bruker EcoATR machine. The samples were scanned over the wave number ranging from 3600 to $400 \mathrm{~cm}^{-1}$

\subsection{Differential Scanning Calorimetry (DSC)}

The possibility of any interaction between Ziprasidone \& polymers amid arrangement of IC \& SD was evaluated via DSC examination \& comparing it with that of pure Ziprasidone using DSC. DSC assessment was carried by differential scanning calorimeter (PerkinElmer 4000) with Software: PYRIS Version-11.1.0.0488, 2009, PerkinElmer, In. Heating of tests was done in an aluminium pan (sample weight utilized $1 \mathrm{mg}$ ) with heating a rate of $10^{\circ} \mathrm{C} / \mathrm{min}$ over a temperature from 30 to $350^{\circ} \mathrm{C}$ using a nitrogen purging at 20 $\mathrm{ml} / \mathrm{min}$.

\subsection{X-ray Diffractometry (XRD)}

XRD spectrum of pure Ziprasidone and SD \&IC were taken at normal temperature with the help of Bruker's AXS D8-advance X-ray diffractometer. Irradiation of tests was carried out with mono-chromatized $\mathrm{Cu} \mathrm{KA} 2$ emission at wavelength $1.5406 \mathrm{~A}^{0}$ and tests were mounted on zerofoundation test holder and subjected to a ceaseless scanning over angles of $3^{\circ}$ to $80^{\circ} 2 \theta$ at a stage size of $0.02^{\circ}$. The diffraction spectrums were gathered with voltage of $40 \mathrm{kV}$ and current of $35 \mathrm{~mA}$ individually. The examining rate was $2^{0}$ $\min -1$.

\subsection{Scanning Electron Microscopy (SEM)}

The topography of pure Ziprasidone and spray dried SD\&IC was looked under a scanning electron microscope (SEM; JEOL model JSM -6390LV) operating at an excitation voltage of $15 \mathrm{kV}$.

\subsection{Saturated Solubility Measurements of ZP}

As indicated by the strategy delineated by Higuchi and J. Connors (1965), Solubility estimations were done. An excess quantity of inclusion complex was included $10 \mathrm{ml}$ distilled water, which was taken in test tubes. The tests were sonicated for $1 \mathrm{~h}$ at room temperature. From that point, the topped test tubes were shaken at 25 or $45 \pm 0.1^{\circ} \mathrm{C}$ for $24 \mathrm{hrs}$. In this manner, the suspensions were sifted and the separated solutions were analysed by UV-spectrophotometer at 207 nm.

\subsection{Dissolution Studies}

These studies were carried out by utilizing USP 8-station dissolution test assembly (Lab India) utilizing USP type II device. Dissolution study was done in a $900 \mathrm{ml}$ of $\mathrm{pH} 7.2$ buffer at $37 \pm 0.5^{\circ} \mathrm{C}$ at $100 \mathrm{rpm} .5 \mathrm{ml}$ tests were withdrawn at time interims of $5,10,15,20,30,45,60 \mathrm{~min}$. The volume of 
dissolution medium was conformed to $900 \mathrm{ml}$ to keep up sink conditions by supplanting every $5 \mathrm{ml}$ aliquot pulled back with $5 \mathrm{ml}$ of new $\mathrm{pH} 7.2$ phosphate buffer. The drug's concentration in tests was dictated by measuring absorbance at $207 \mathrm{~nm}$. Aggregate percent drug release was ascertained at each time interim. Pure Ziprasidone was utilized as control for examination.

\subsubsection{In-Vivo Absorption Study in Wistar Rats}

Wistar-strain rats of either sex (180-220 g) were made available by the Animal House, college of Pharmacy, Nashik, India. They were housed under normal laboratory conditions. Rats were maintained on standard rodent chow and tap water. The Institutional Animal Ethical Committee (IAEC/Feb.2016/08) gave approval for the experimental methods.

The rats were kept with empty food however, but they were given clear reach to water $24 \mathrm{~h}$ earlier the day of the experiment. 3 rats group were utilized in the study. Random assignment of 6 rats to each treatment group was done. To individual group oral administration of plain Ziprasidone aqueous suspension, Ziprasidone-SD (solid dispersion) and third group was control group, was done. Sample of Ziprasidone powder $(4 \mathrm{mg}$ ), Ziprasidone-SD (equivalent to Ziprasidone $4 \mathrm{mg}$ ), were mixed uniformly by accurately weighing $\&$ dispersing it into water $(5 \mathrm{ml})$ for $30 \mathrm{~s}$ before to dosing. To rats, individual preparation was given utilizing oral gavage (an animal feeding needle). Blood samples $(0.5$ $\mathrm{ml})$ were collected via tail vein at $30,60,120,240,360$ and 720 min after oral administration into EDTA microcentrifuge tubes. Centrifugation of samples was done at 10,000 rpm $10^{\circ} \mathrm{C}$ for $20 \mathrm{~min}$ where samples of plasma separated, and 0.5 $\mathrm{ml}$ of cold acetonitrile add up to the plasma sample for precipitating the protein. The processed samples's centrifugation was again done at $10,000 \mathrm{rpm} 10^{\circ} \mathrm{C}$ for 20 min, \& supernatant liquid was stored in refrigerator until analyzed by HPLC [51].

\subsubsection{HPLC Analysis of Plasma Samples}

Standard solutions of $2,4,6,8$, and $10 \mu$ l were prepared and calibration curve was plotted by HPLC. $20 \mu \mathrm{l}$ of plasma sample was put in into HPLC. Concentration of Ziprasidone in plasma was then further determined by calculating area under curve of chromatogram.

HPLC (Binary HPLC pump provided with a UV visible 2000 detector, Waters 1525, Singapore) was utilized for the assessment of plasma samples. The sorting was performed using a Cosmosil C18 packed column $(150 \mathrm{~mm} \times 4.6 \mathrm{~mm}, 5$ $\mu \mathrm{m})$ at $276 \mathrm{~nm}$. The mobile phase consisted of a mixing of phosphate buffer having $\mathrm{pH} 3 \pm 0.5$ with acetonitrile $(60: 40)$ operating at a flow rate of $1 \mathrm{ml} / \mathrm{min}$ [52].

\subsection{Biological Studies}

Foot shock induced aggression

The animals were splited into 5 groups of 12 mice (6 pairs of male mice) per group. The vehicles are (DMSO (Dimethyl sulphoxide); $0.5 \mathrm{ml} / \mathrm{kg}$, i.p.), haloperidol (1 $\mathrm{mg} / \mathrm{kg}$, i.p.) utilized as a standard and optimized formulation $(40 \mathrm{mg} / \mathrm{kg})$ were given i.p., 30 minutes preceding the experiment. Foot shock-induced aggression (FSIA) behaviour was elicited in pairs of mice by applying a series of impulses through with an electronic stimulator to a grid floor for 3 minutes. Offensive activeness was measured in pairs of mice using 2 factors i.e. number of fights and latency to fight $[53,54]$.

\section{Results and Discussion}

\subsection{Solubility Study}

The solubility profiles for prepared formulations are depicted in figure 1 . The solubility of inclusion complex with $\mathrm{HP} \beta \mathrm{CD}$ prepared by spray drying method in distilled water was found to show, an almost 15.7 fold increase in solubility respectively as compared to pure drug. Spray drying has converted crystal form of Ziprasidone to amorphous which in effect increases its apparent solubility in water [55].

Among various solvents that were screened methanol was selected as the solvent for ZP due to its higher solubilization potential and low boiling point. The saturation solubility of solid dispersion by spray drying with Kollidon, Soluplus, Pluronic (F-127) in distilled water was found to show, an almost $13.7,17.1,8.59$ fold increase in solubility respectively than pure drug. Spray drying technique combined with best hydrophilic polymers was found to be successful in preparing solid dispersions of ZP [56]. The drug to polymer ratio also affects the solubility of Ziprasidone, thus optimum ratio was selected based on solubility enhancement [57]. While for solid dispersion by solvent evaporation method with hydrophilic polymers like Kollidon, Soluplus, Pluronic (F-127) in distilled water was found to show, an almost 8.7, 11.2, 3.9 fold increase in solubility respectively than pure drug [58].

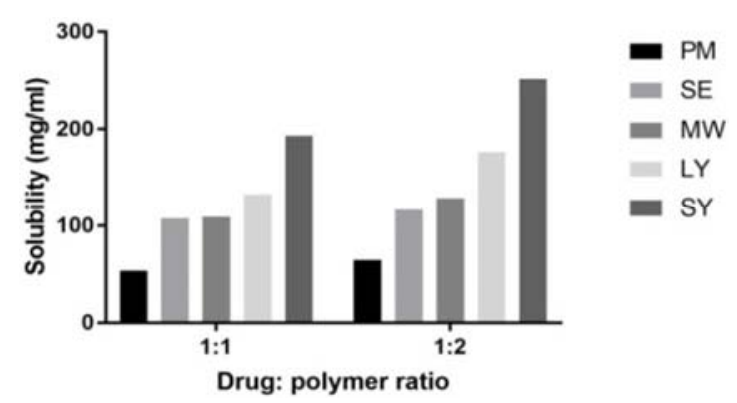

a.

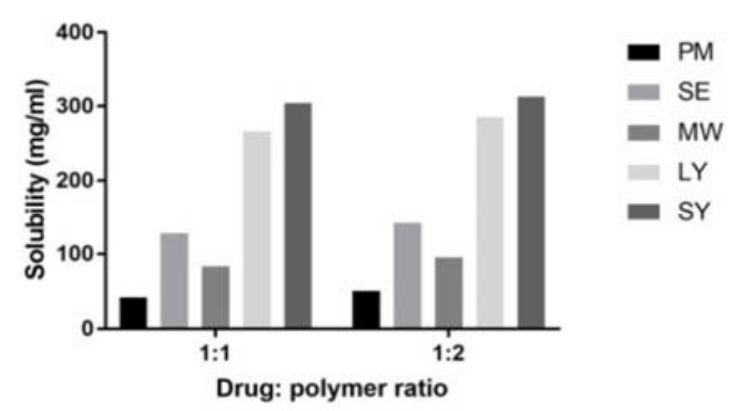

b. 


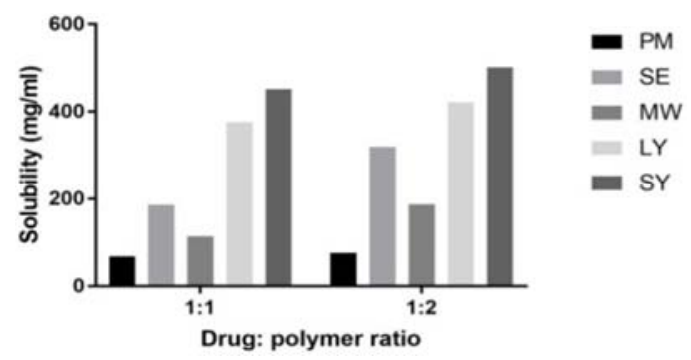

c.

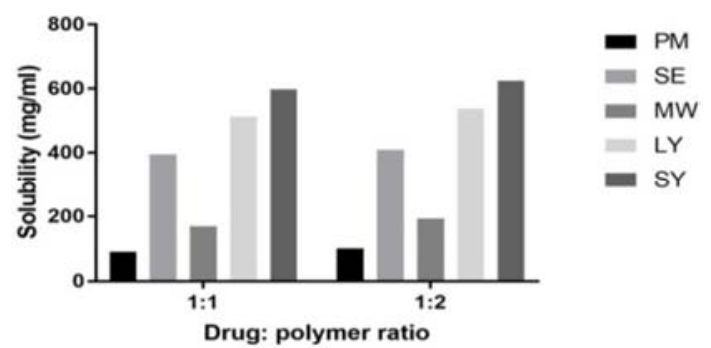

d.

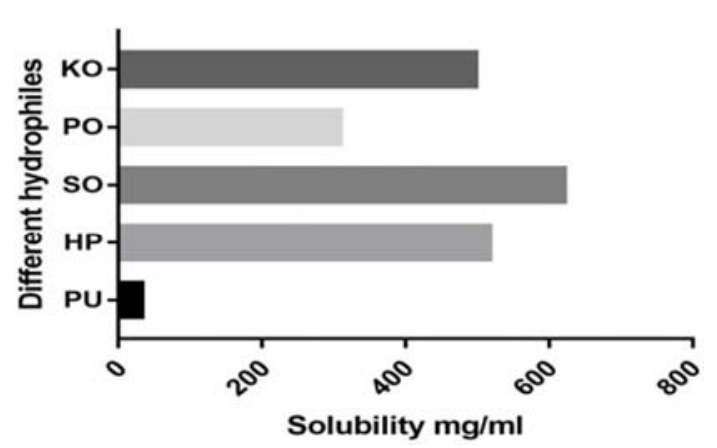

e.

Figure 1. Comparative solubility profiles of a. HP $\beta C D-I C$ (Inclusion complexation); b. Pluronic-SD; c. Soluplus-SD; d. Kollidon-SD; e. All hydrophiles for solubility enhancement of Ziprasidone.

(Where KO: Kollidon, PO: Poloxamer, SO: Soluplus, HP: HP $\beta C D$, PU: Pure Ziprasidone)

\section{2. $A T R$}

The ATR spectra obtained for the prepared formulations are displayed in figure $2 \mathrm{a}-2 \mathrm{~d}$. The IR spectrum of solid dispersion showed peaks of decreased intensity and also some peaks of Ziprasidone were disappeared indicating formation of complex in solid state.

The ATR spectrum of plain Ziprasidone showed vibrational peaks at $3412.57 \mathrm{~cm}^{-1}$ for N-H (amine), 2918.86 $\mathrm{cm}^{-1}$ for $\mathrm{C}-\mathrm{H}, 1717.03 \mathrm{~cm}^{-1}$ for $\mathrm{C}=\mathrm{O}$ (amide), $1630.09 \mathrm{~cm}^{-1}$ for $\mathrm{C}=\mathrm{C}$ (alkene), $1473.06 \& 1397.57 \mathrm{~cm}^{-1}$ for $\mathrm{C}=\mathrm{C}$ (of aromatic), $1265.29 \& 1177.98 \mathrm{~cm}^{-1}$ for $\mathrm{N}-\mathrm{H}$ (bend), 969.62 $\mathrm{cm}^{-1}$ for $=\mathrm{C}-\mathrm{H}, 752.01 \mathrm{~cm}^{-1}$ for $-\mathrm{C}-\mathrm{Cl}$-(alkyl halide).

In all the formulations, vibrational peak at $1110 \mathrm{~cm}^{-1}$ was noted. Other peaks were shifted to higher wavenumber suggesting formation of new solid state.

In Soluplus-SD, vibrational peak at $3426.16 \mathrm{~cm}^{-1}$ of $\mathrm{O}-\mathrm{H}$ was observed and also carbonyl peak was shifted to 1734.51 $\mathrm{cm}^{-1}$ indicating hydrogen bond formation between Ziprasidone and Soluplus.
For Pluronic-SD, also vibrational peak at $3400 \mathrm{~cm}^{-1}$ was observed shifting of carbonyl peaks $\&$ other peaks at higher wavenumber.

For Kollidon, prominent peak was observed at 1032.09 $\mathrm{cm}^{-1}$ along with $\mathrm{O}-\mathrm{H}$ peak at $3012.5 \mathrm{~cm}^{-1}$ wavenumber while for $\mathrm{HP} \beta \mathrm{CD}$-IC it was at $3454.76 \mathrm{~cm}^{-1}$ wavenumber indicating $\mathrm{O}-\mathrm{H}$ bond formation i.e. hydrogen bond interaction between polymer and Ziprasidone \& this mechanism might be responsible for solubility \& dissolution rate enhancement of poorly soluble Ziprasidone.

The stretching vibration of functional group were found to be within range in all solid dispersions as well as in physical mixture indicating absence of any significant chemical interaction in solid state.

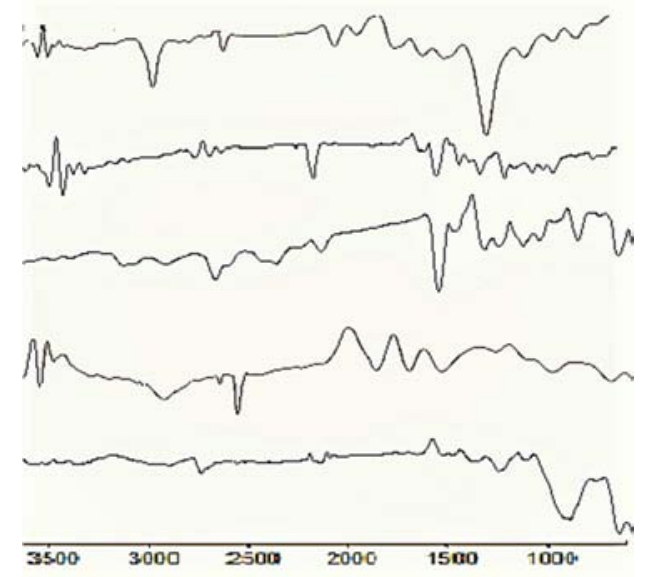

Figure 2a. ATR spectras of Soluplus Sds: SE, SY, Pure Ziprasidone, LY, MW.

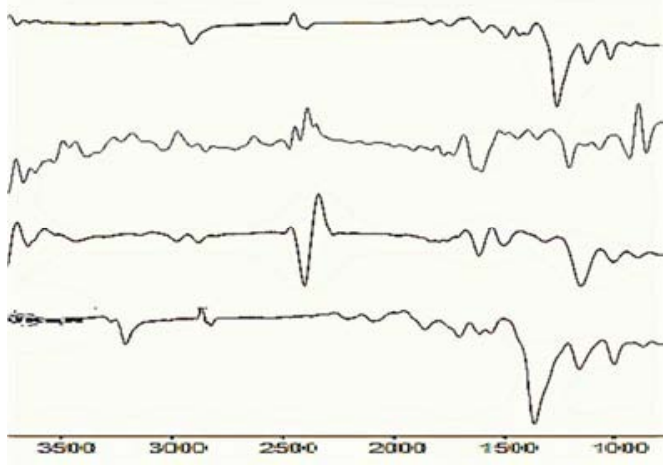

Figure 2b. ATR spectras of Pluronic Sds: SE, SY, MW, LY.

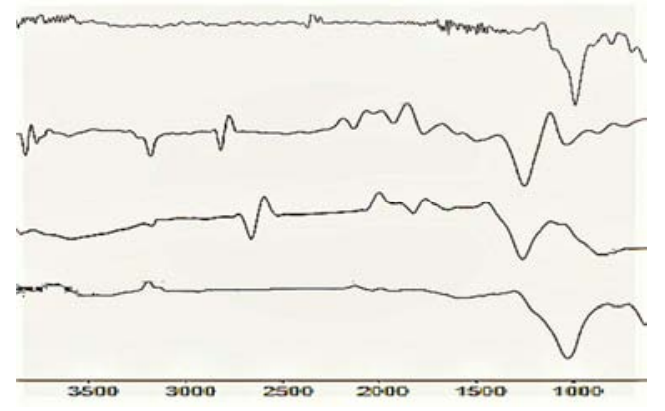

Figure 2c. ATR spectra of HPBCD-IC: SY, PM, LY, MW. 


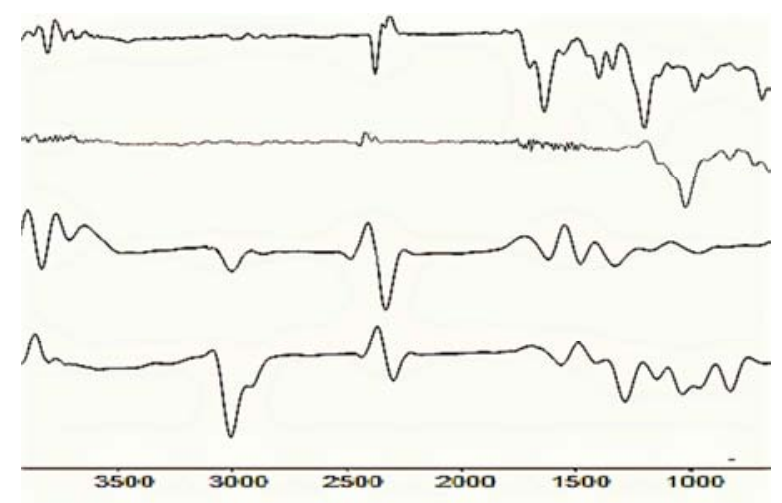

Figure 2d. ATR spectras of Kollidon Sds prepared by: SE, SY, LY, MW.

Where SE: Solvent Evaporation, SY: Spray Drying, LY: Lyophilization, MW: Microwave Irradiation.

\subsection{DSC}

The DSC spectra of pure Ziprasidone and the prepared formulation by spray drying method are illustrated in Figure 3.

The DSC spectrum of pure Ziprasidone showed two peaks in its thermogram, one at $84.15^{\circ} \mathrm{C}$ due to removal of hydrochloride molecule \& other one at $290.66^{\circ} \mathrm{C}$ owing to melting endotherm of Ziprasidone that corresponds to its melting point $\left(\sim 300^{\circ} \mathrm{C}\right)$. Whereas, all the prepared formulations showed broadening of the endotherm with decreasing the heat energy required for the phase change. This change in thermogram represented the amorphous nature of the prepared formulation responsible for the modification in solubility as well as dissolution rate improvement of Ziprasidone.

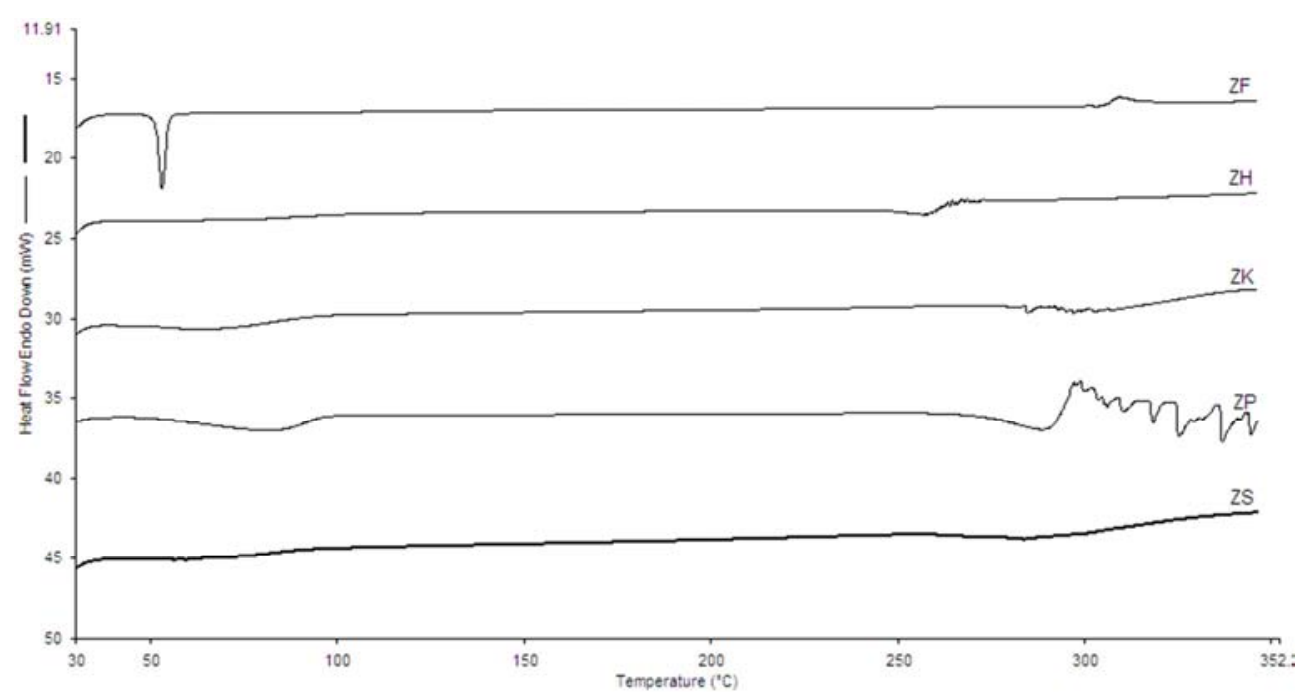

Figure 3. DSC thermogram of binary system prepared by spray drying method ZF: SD with Pluronic; ZH:IC with HPBCD; ZK: SD with Kollidon; ZP:Ziprasidone; ZS: SD with Soluplus.

\subsection{XRD}

The XRD spectras are illustrated in figure 4. Diffraction pattern of pure drug showed high-intensity distinctive diffraction peak peaks at $2 \theta$ diffraction angle of $10.74,14.67$, 17.93, 21.57, 26.32, 27.81, and 28.65. XRD spectra of drug where it displayed all sharp peaks pointing its crystal form [59].

XRD spectra of drug-Soluplus, Kollidon, Pluronic (F127) spray dried solid dispersion showed a significant reduction in the number and intensity of peaks indicating drug entrapment as well as amorphization of the drug. Thus, for spray dried solid dispersions it showed broad amorphous halo peak and no evidence of sharp diffraction peaks.

XRD spectrum of plain drug demonstrated its completely crystalline nature whereas, XRD spectra of drug- HP $\beta C D$ spray dried inclusion complexation showed a significant reduction in the number and intensity of peaks i.e. diffused form indicating drug entrapment as well as amorphization of the drug. Hence, transformations of drug from crystal form to amorphous.
This conversion of crystalline drug to amorphous form due to use of spray drying may be the reason behind apparent solubility \& dissolution enhancement of pure Ziprasidone in prepared formulations.

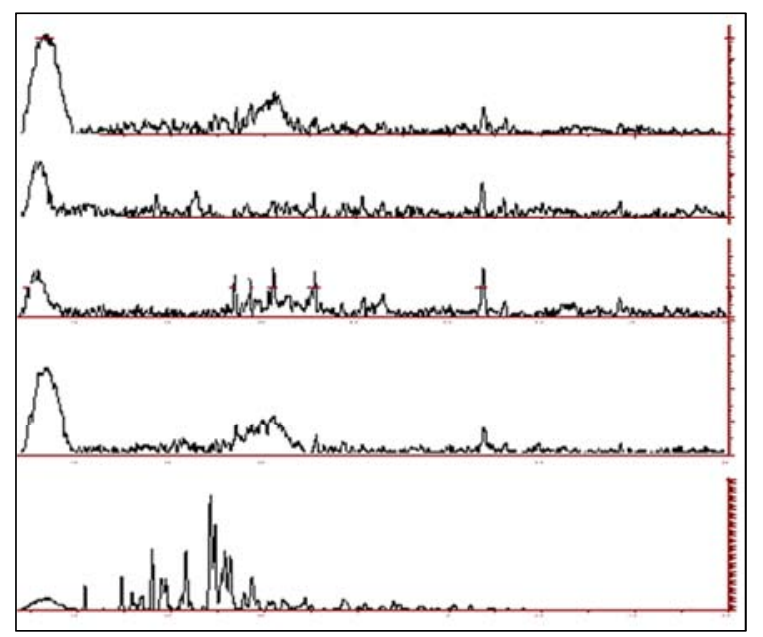

Figure 4. XRD spectrum of HPBCD-IC, Pluronic-SD, Soluplus-SD, Kollidon-SD, And Pure Ziprasidone. 


\subsection{SEM}

Scanning electron micrographs (SEM) of prepared formulations along with pure Ziprasidone are illustrated in figure 5. SEM of pure drug appeared as angulate formed smooth surfaced crystals of varied sizes with well-formed line. Nonetheless, ZP-HPßCD inclusion complex was appeared as spherical and wrinkled appearance of varying sizes with smooth surface $\&$ as homogeneous system.

SEM of pure drug appeared as smooth-surfaced rectangular crystalline structures of varying sizes with well- developed edges. However, ZP-Soluplus, ZP- Kollidon, ZPPluronic SDs were appeared as irregular shaped particles of varying sizes with smooth surface. The particles of SDs show a spherical and wrinkled appearance, indicating the drug substance is embedded within the polymer matrix. It also seem to be as homogeneous system where polymer is uniformly distributed all over drug. In contrast, there was no crystal structure of ZP in SDs (solid dispersions), indicating the transformation of ZP into an amorphous form.
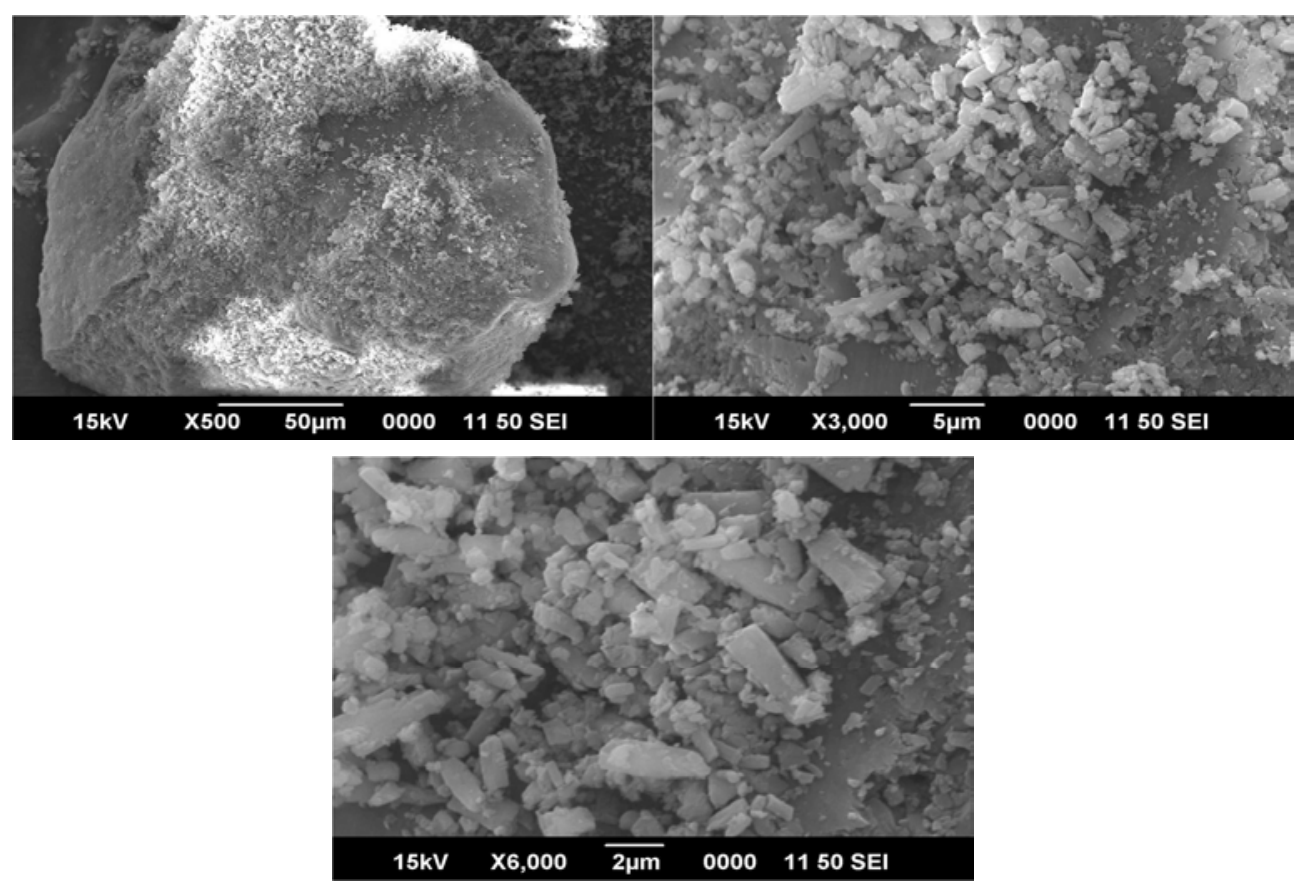

Figure 5a. SEM of pure ziprasidone.
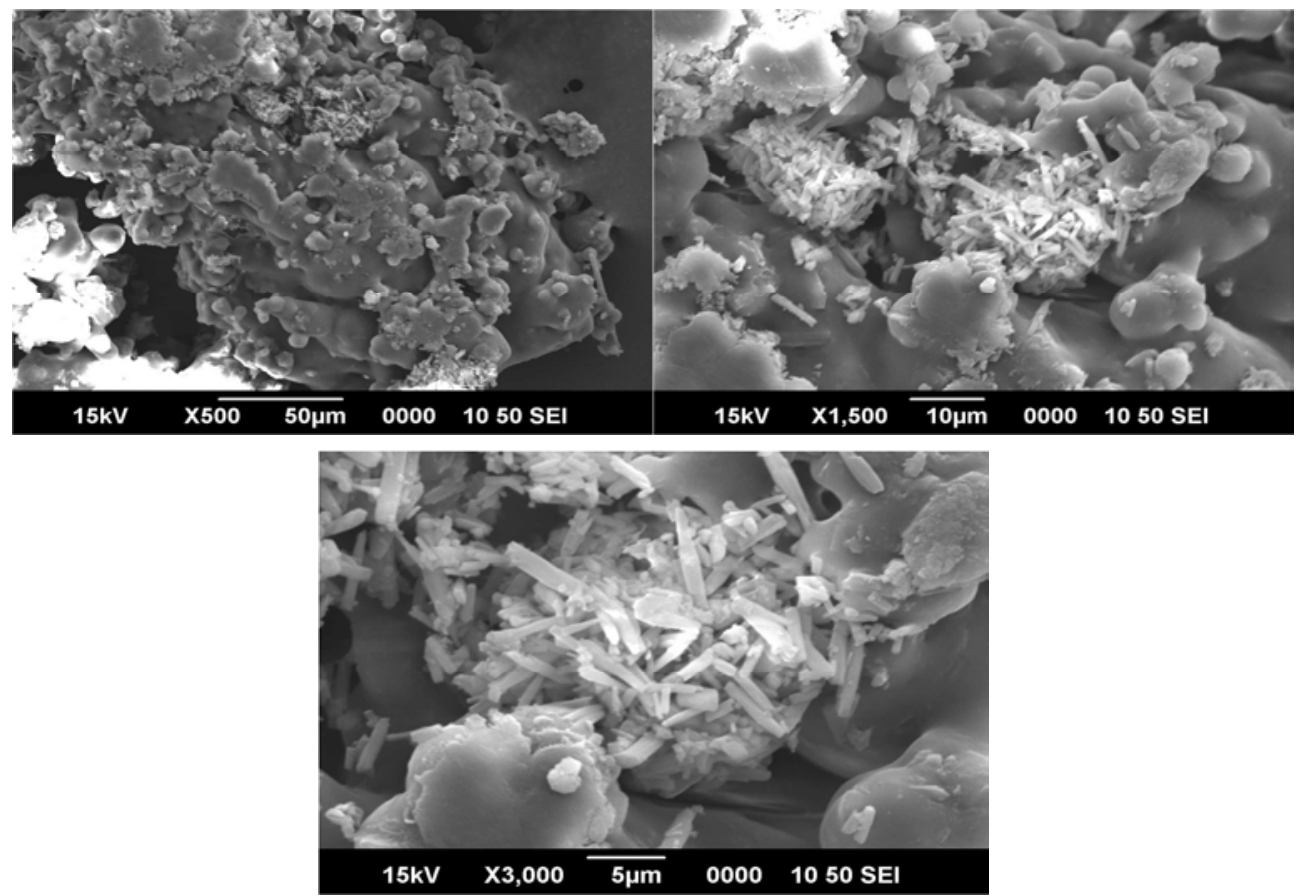

Figure 5b. SEM of Ziprasidone-Soluplus-SD 

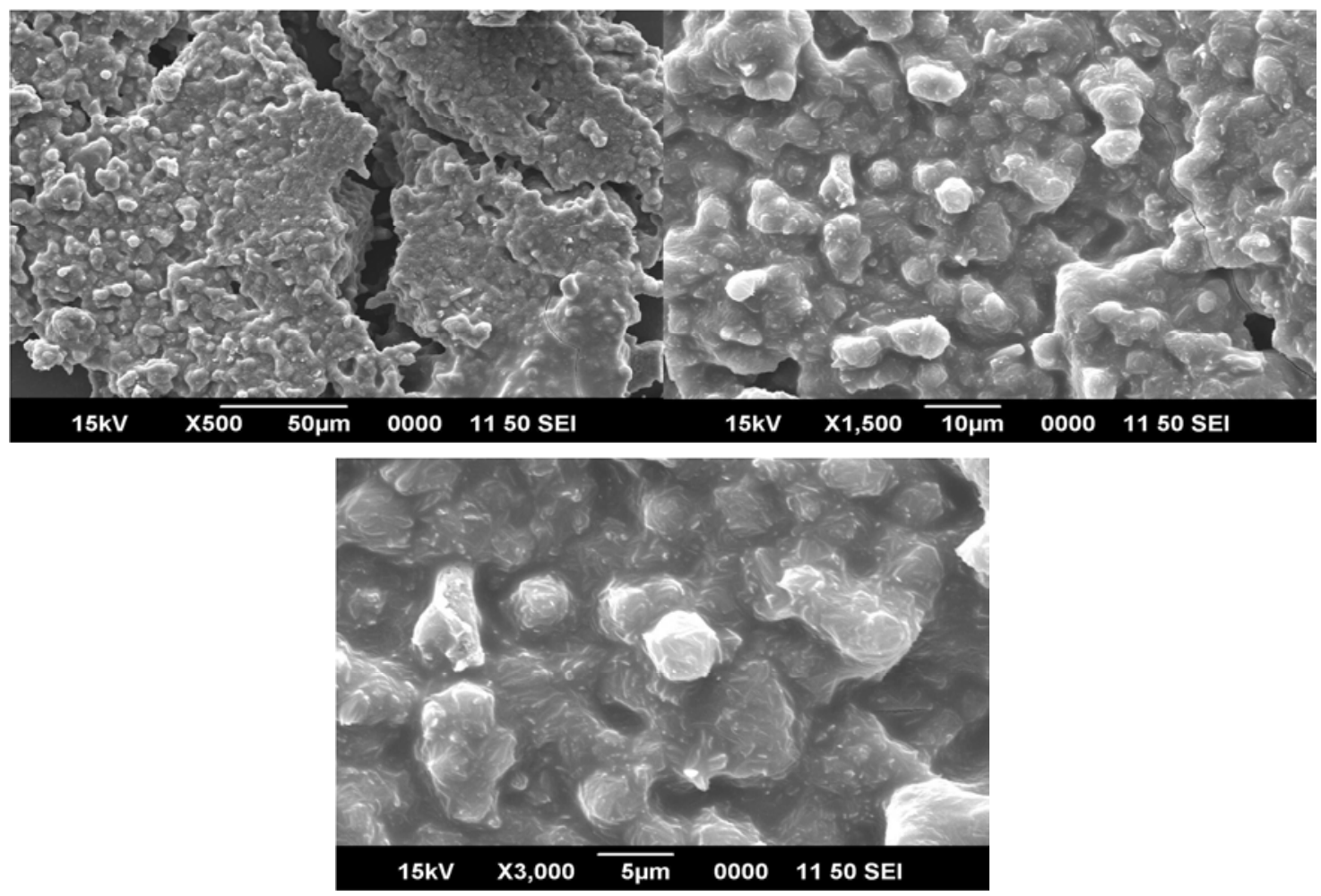

Figure 5c. SEM of Ziprasidone-HPßCD-IC.
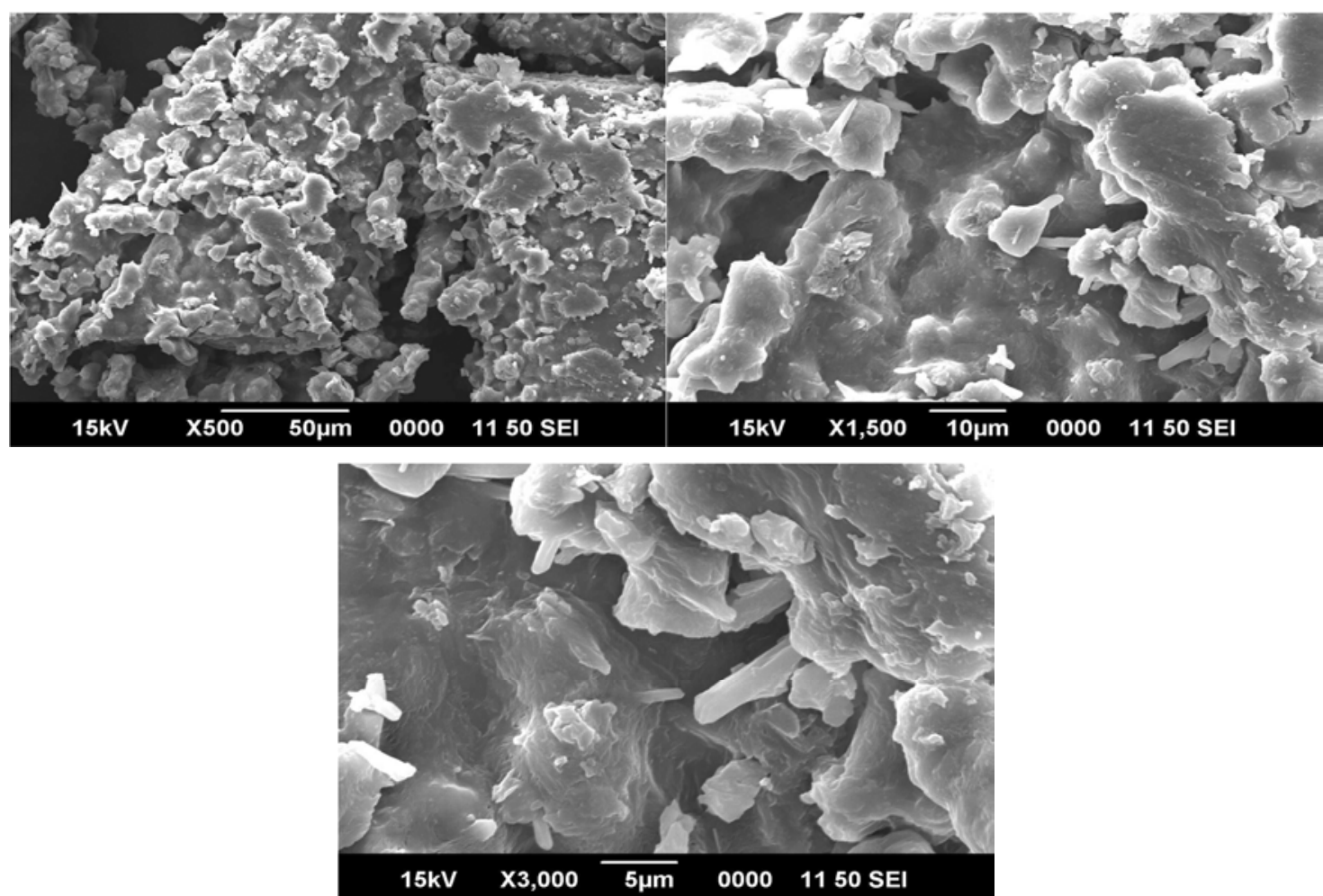

Figure 5d. SEM of Ziprasidone-Pluronic (F127)-SD

\subsection{In Vitro Dissolution}

The dissolution profiles of the formulations are depicted in the figure 6 . All the prepared formulations demonstrated increase in dissolution rate compared to pure Ziprasidone.
In-vitro dissolution studies revealed that the inclusion complexes released the drug to a greater extent as compared to pure ZP. Binary complex with HP $\beta C D$ showed a release of $92.36 \%$ in $\mathrm{pH} 7.2$ buffer in $20 \mathrm{~min}$.

The enhanced dissolution may be due to inclusion complex 
formation as well as raised mechanistic impinging during dissolution [60, 61].

The in vitro dissolution studies of solid dispersion by spray drying with Kollidon, F-127 in 7.2 po4 buffer with $92.05 \%$, and $73.3 \%$ drug being released within $20 \mathrm{~min}$, Whereas in case of Soluplus almost $92.97 \%$,drug was released in $20 \mathrm{~min}$ in 7.2 po4 buffer.

As during spray drying, the particle size is diminished leading to increased effective surface area available for dissolution \& formation of high energetic, highly soluble amorphous form generation (as evident from XRD, SEM) might be the reason behind dissolution rate enhancement of formulations [62].

In case of ZP, spray dried SD with Soluplus formulation showed a significant improvement in saturation solubility and dissolution rate and hence further studies were conducted on it. For determining $t_{\max }$ for the in vivo study earlier studies were taken into account $[63,64]$.
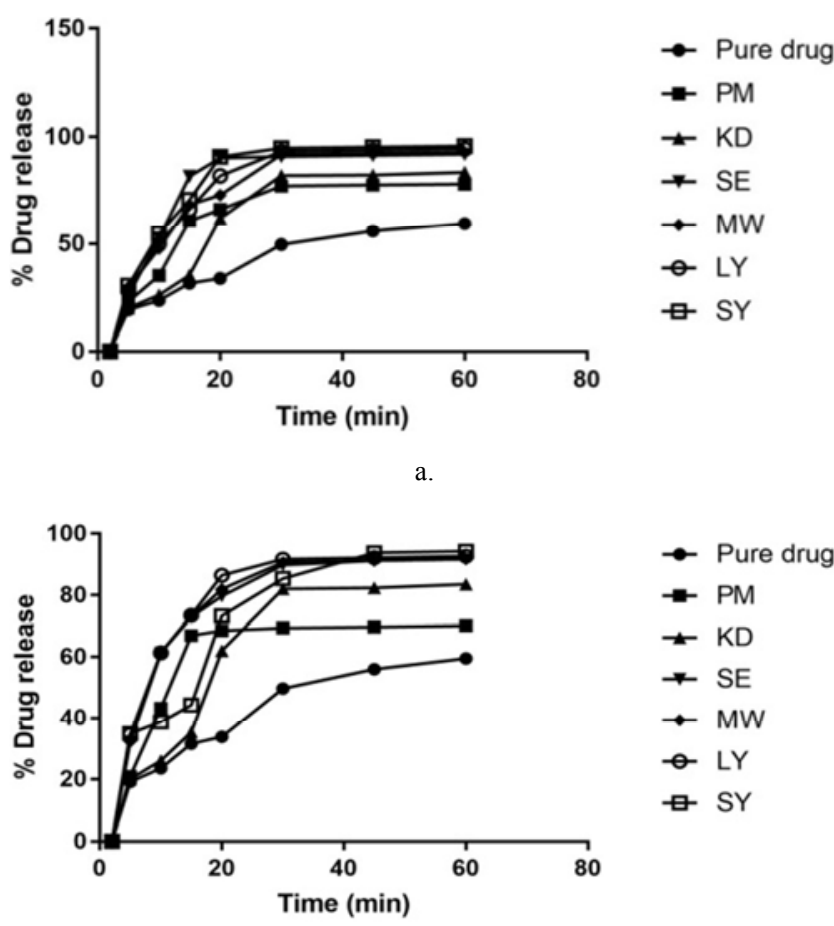

- Pure drug

$\rightarrow \mathrm{PM}$

$\pm \mathrm{KD}$

$\rightarrow$ SE

$\rightarrow \mathrm{MW}$

- LY

曰 SY

b.

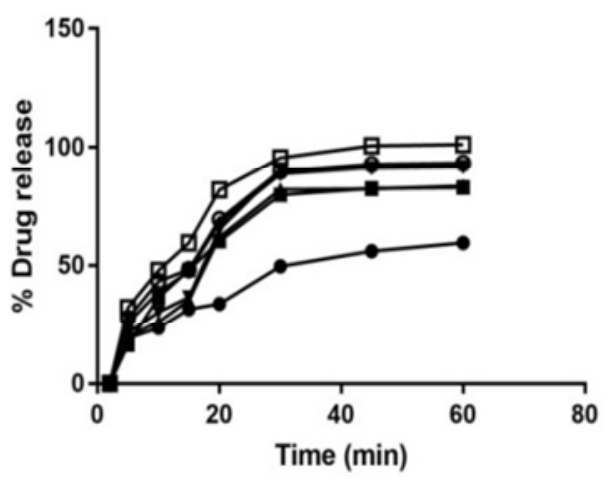

- Pure drug

$\Rightarrow \mathrm{PM}$

$\downarrow \mathrm{KD}$

* SE

$\rightarrow \mathrm{MW}$

$\theta$ LY

๑ SY

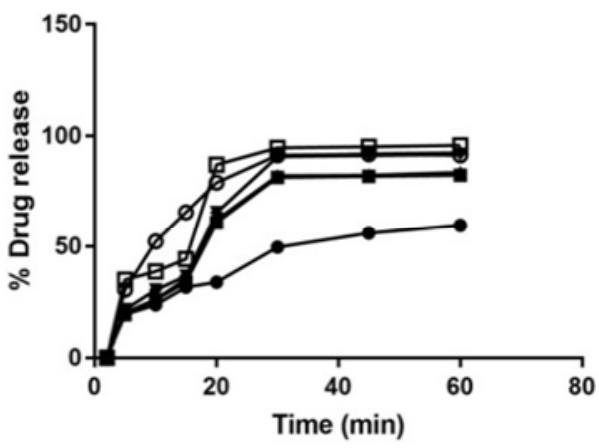

- Pure drug

- PM

$\pm \mathrm{KD}$

* SE

$\rightarrow$ MW

$\theta$ LY

๑ SY

d.

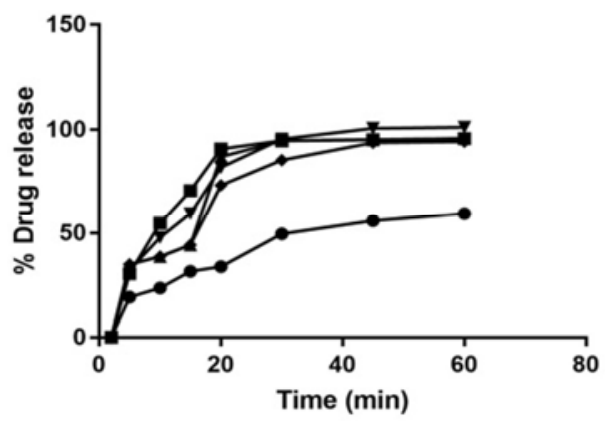

-- Pure drug

- $\mathrm{KO}$

$\mp \mathrm{HP}$

$\rightarrow \mathrm{SO}$

$\rightarrow$ PO

Figure 6. Comparative dissolution profile for solubilizing methods of a. Kollidon-SD, b. Pluronic-SD, c. Soluplus-SD, d. HP $\beta C D-I C$, e. Comparative dissolution profile for polymers with spray drying.

(Where KO: Kollidon, PO: Poloxamer, SO: Soluplus, HP: HP $\beta C D$, PU: Pure Ziprasidone)

\subsection{Biological Studies}

The pharmacodynamic study was carried out using control, standard, pure drug \& optimised formulation where calming effect was determined using 2 observational parameters. The spray dried formulation showed higher latency to fight as compared to pure drug also the numbers of fights were decreased in case of ZP-Soluplus solid dispersion than pure ZP. Foot shock-induced aggression (FSIA) (Aggressive behaviour) was measured in pairs of mice using two parameters number of fights and latency to fight.

Table 1. Foot shock-induced aggression (FSIA) (Aggressive behaviour).

\begin{tabular}{lll}
\hline Compound (40 $\mathbf{~ m g} / \mathbf{k g}, \mathbf{i . p .})$ & Latency to fight & Number of fights \\
\hline DMSO (vehicle) & $31.5 \pm 8.07$ & $62.66 \pm 5.50$ \\
Haloperidol & $286.64 \pm 9.07$ & $7.67 \pm 1.02$ \\
Ziprasidone & $215.67 \pm 15.23$ & $9.56 \pm 2.06$ \\
Ziprasidone SD & $225.67 \pm 15.23$ & $8.24 \pm 2.06$ \\
\hline
\end{tabular}

\subsection{In Vivo Study}

The pharmacokinetic study conducted for formulations which displayed in figure 7 showed increase in oral absorption for all prepared formulations. It was found that significant ( $p$-value $<0.05$ ) enhancement in bioavailability of Ziprasidone was observed from formulations as compared with pure Ziprasidone suspension. The extent of absorption of Ziprasidone was significantly increased in presence of 
Soluplus $(\mathrm{p}<0.05)$. This was accompanied by a significant increase in the AUC.

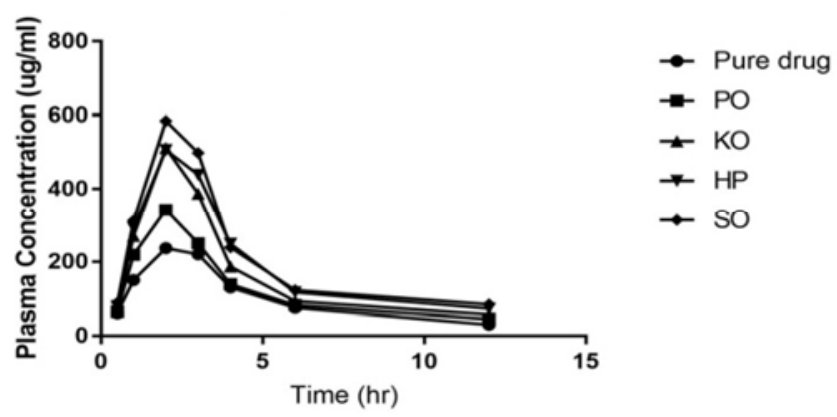

Figure 7. Mean plasma concentration-time curve of prepared formulations.

Plasma concentration vs. time profiles after oral administration of ziprasidone formulated as Solid dispersions \& inclusion complex compared with plain ziprasidone pharmacokinetics after dosing both as aqueous suspensions. Out of 5 mean plasma concentration time curve obtained, Soluplus-SD showed highest AUC than other formulations as well as than plain Ziprasidone. This is consistent with solubility and dissolution data, which suggesting that Ziprasidone's oral bioavailability can be increased by increasing its apparent solubility using appropriate polymer \& suitable technique. Here, Soluplus solid dispersion approach proved to be good in enhancing the absorption of Ziprasidone along with spray drying technology.

\section{Conclusion}

The present work demonstrates the outlook of development of a Ziprasidone formulation using spray drying technique. This comparative study using Kollidon VA 64, Pluronic (F 127), Soluplus and HPßCD gave interesting insights about solubility enhancement of Ziprasidone such as the poor aqueous solubility of Ziprasidone may be getting over by amorphous form formation \& utilizing appropriate excipient with suitable solubility enhancement technique. Spray drying with Soluplus proved to be a suitable method for ZP as compared to complexation with HP $\beta C D$. It is a comparatively simplex with easy scale-up. The in vivo study demonstrated the increase in oral absorption of solid dispersion as compared to pure Ziprasidone which can lead to dose minimization in Schizophrenia treatment with increasing the chances of patient compliance \& adherence to treatment.

\section{Future Scope}

Although this work utilized different solubility enhancing methods as well as utilized different polymers for solubility improvement of poorly soluble Ziprasidone, but the underlying mechanisms responsible for the gained outcome has to be understood using recent molecular simulation or molecular modelling approaches.

\section{References}

[1] WHO. Draft comprehensive mental health action plan 20132020. http://apps.who.int/gb/ebwha/pdf_fi les/WHA66/A66 10Rev1-en. pdf

[2] WHO. (2008) mhGAP Mental Health Gap Action Programme: scaling up care for mental, neurological and substance use disorders. Geneva: World Health Organization.

[3] Lee H, Tsai S, Lin H, Chen C (2006) The association between psychiatrist numbers and hospitalization costs for schizophrenia patients: a population-based study. Schizophr Res 81(2-3):283-290.

[4] Rossler W, Salize H, Van J, Riecher-Rossler A (2005) Size of burden of schizophrenia and psychotic disorders. Eur Neuropsychopharmacol 15(4):399-409.

[5] Zhai J., Guo X., Chen M., Zhao J., Su Z. (2013) An investigation of economic costs of schizophrenia in two areas of China International Journal of Mental Health Systems 7:26.

[6] Chong H., Teoh S., Wu D., Kotirum S., Chiou C. Chaiyakunapruk N. (2016) Global economic burden of schizophrenia: a systematic review. Neuropsychiatric Disease and Treatment 12:357-373.

[7] Davis J, Matalon L, Watanabe M. (1994) Depot antipsychotic drugs. Place in therapy. Drugs 47:741-773.

[8] Dencker S. (1984) The risk/benefit ratio of depot neuroleptics: a Scandinavian perspective. J. Clin. Psychiatry 45, 22-27.

[9] Barnes T, Curson D. (1994) Long-term depot antipsychotics. A risk-benefit assessment. Drug. Saf. 10: 464-479.

[10] Ereshefsky L, Saklad S, Jann M. (1984) Future of depot neuroleptic therapy: pharmacokinetic and pharmacodynamic approaches. J. Clin. Psychiatry 45:50-59.

[11] Heres S, Hamann J, Kissling W, Leucht S. (2006) Attitudes of psychiatrics toward antipsychotic depot medication. J. Clin. Psychiatry 67:1948-1953.

[12] Szasz T: Where does psychiatry go? In: Ideology and Insanity. (1970) Essays on the Psychiatric Dehumanization of Man. Szasz T (Ed.). Anchor Books, New York, NY, USA, 213-238.

[13] Olivares J, Pinal B., Cinos C. (2011) Comparison of longacting antipsychotic injection and oral antipsychotics in schizophrenia Neuropsychiatry 1(3):275-289.

[14] Stahl S., Shayegan, D., (2003) The psychopharmacology of ziprasidone: receptorbinding properties and real-world psychiatric practice. J. Clin. Psychiatry 64: 6-12.

[15] Clinicaltrils.gov [Internet homepage] https://clinicaltrials.gov/ct2/results?term=ziprasidone\&pg=2

[16] O’ Neil M, Heckelman P, Koch C, Roman K, Kenny C, D'Arecca M. (2006) Ziprasidone Hydrochloride, In: The Merck Index - An encyclopedia of chemicals, drugs and biological, Merck Research Laboratory, Division of Merck \& Co., Inc., Whitehouse Station, New Jersey, 14th Edition. 10307.

[17] Sweetman S. (2009) Ziprasidone Hydrochloride, In: Martindale-The Complete Drug Reference, Pharmaceutical Press, London, and 36th Edition. 1036. 
[18] Miceli J, Wilner K, Swan S, Tensfeldt T. (2005) Pharmacokinetics, safety, and tolerability of intramuscular Ziprasidone in healthy volunteers, J Clin Pharmacol 45: 62030 .

[19] Preskorn S. (2005) Pharmacokinetics and therapeutics of acute intramuscular ziprasidone, Clin Pharmacokinet, 44: 1117-33.

[20] Miceli J, Smith M, Robarge L, Morse T, Laurent A. (2000) The effects of ketoconazole on ziprasidone pharmacokinetics - a placebo-controlled crossovers study in healthy volunteers, British Journal of Clinical Pharmacology 49(S1): 71-76.

[21] Martini L, Crowley P. (2011) Controlling drug release in oral product development programs: An industrial Perspective: In Controlled release in oral drug delivery. Springer, New York $45-70$

[22] Geodon ${ }^{\circledR}$ (Revised 2009) [U.S. Prescribing Information including Patient Summary of Information], Pfizer Inc.

[23] Daniel, D. (2003) Tolerability of ziprasidone: an expanding perspective. J. Clin. Psychiatry 64, 40-49.

[24] Patel, N., Keck J. (2006) Ziprasidone: efficacy and safety in patients with bipolar disorder. Expert Rev. Neurotherapeutics 6: 1129-1138.

[25] Zimbroff D., Allen M, Battaglia, J., Citrome, L., Fishkind A., Francis A., Herr Daniel, L., Hughes, D., Martel, M., Preval, H., Ross, R. (2005) Best clinical practice with ziprasidone IM: update after 2 years of experience. CNS Spectr. 10:1-15.

[26] Greenberg W., Citrome L. (2007) Ziprasidone for schizophrenia and bipolar disorder: a review of the Clinical trials. CNS Drug Rev. 13:137-177.

[27] Harrison, T., Scott, L. Ziprasidone: a review of its use in schizophrenia and schizoaffective disorder. CNS Drugs 20:1027-1052.

[28] Bernardo, M., Azanza, J., Rubio-Terres, C., Rejas, J. (2006) Cost-effectiveness analysis of schizophrenia relapse prevention: an economic evaluation of the ZEUS (ziprasidoneextended-use-in-schizophrenia) study in Spanish. Clin. Drug Invest. 26:447-457.

[29] Bernardo, M.,Azanza, JR., Rubio-Terres, C., Rejas, J. (2007) Cost-effectiveness analysis of the prevention of relapse of schizophrenia in the longitudinal study ziprasidone extended use in schizophrenia (ZEUS). Actas Esp. Psiquiatr. 35:259-262.

[30] Bobes, J., Canas, F., Rejas, J., Mackell, J. (2004) Economic consequences of the adverse reactions related with antipsychotics: an economic model comparing tolerability of ziprasidone, olanzapine, risperidone, and haloperidol in Spain. Prog. Neuropsychopharmacol. Biol. Psychiatry 28: 1287-1297.

[31] Miceli, J., Wilner, K., Hansen, R., Johnson, A., Apseloff, G., Gerber, N. (2000) Single- and multiple-dose pharmacokinetics of ziprasidone under nonfasting conditions in healthy male volunteers. Br. J. Clin. Pharmacol. 49: 5S-13S.

[32] Lincoln J., Stewart Mark, E., Preskorn Sheldon, H. (2010) How sequential studies inform drug development: evaluating the effect of food intake on optimal bioavailability of ziprasidone. J. Psychiatr. Pract. 16:103-114.

[33] Perkins, D. (2002) Predictors of noncompliance in patients with schizophrenia. J. Clin. Psychiatry 63: 1121-1128.

[34] Stella, V., Nti-Addae, K. (2007) Prodrug strategies to overcome poor water solubility. Adv. Drug Deliv. Rev. 59: 677-694.

[35] Babu, N., Nangia, A. (2011) Solubility advantage of amorphous drugs and pharmaceutical cocrystals. Cryst. Growth Des. 11:2662-2679.

[36] Porter, C., Pouton, C., Cuine, J., Charman, W. (2008) Enhancing intestinal drug solubilization using lipid-based delivery systems. Adv. Drug Deliv. Rev. 60:673-691.

[37] Tang J., Sun, J., He Z. (2007) Self-emulsifying drug delivery systems: strategy for improving oral delivery of poorly soluble drugs. Curr. Drug Ther. 2:85-93.

[38] Brewster M., Loftsson, T. (2007) Cyclodextrins as pharmaceutical solubilizers. Adv. Drug Deliv. Rev. 59:645666.

[39] Friesen, D., Shanker, R., Crew M., Smithey, D., Curatolo, W, Nightingale, J. (2008) Hydroxypropyl methylcellulose acetate succinate-based spray-dried dispersions: an overview. Mol. Pharm. 5: 1003-1019

[40] Usha Y., Angel T., Udupa, N. (2010) Nanotechnology: perspectives on solubility/bioavailability enhancement. Pharma Rev. 8:59-66.

[41] Hong J. (2011) Effect of Cyclodextrin Derivation and Amorphous State of Complex on Accelerated Degradation of Ziprasidone. Journal of Pharmaceutical Sciences. 100(7); 2703-2716.

[42] Kim Y. (1998) Inclusion complexation of ziprasidone mesylate with $\beta$-cyclodextrin sulfobutyl ether. J Pharm Sci. 87(12):1560-7.

[43] Thombre A, Shah J, Sagawa K. (2012) In vitro and in vivo characterization of amorphous, nanocrystalline, and crystalline ziprasidone formulations. Int J Pharm 428:8-17.

[44] Thombre A, Herbig S, Alderman J. (2011) Improved ziprasidone formulations with enhanced bioavailability in the fasted state and a reduced food effect. Pharm Res 28:3159-70.

[45] Thombre A, Shamblin S, Malhotra B, Connor A, Wilding I, Caldwell W. (2015) Pharmacoscintigraphy studies to assess the feasibility of a controlled release formulation of ziprasidone. J Control Release 213:10-7.

[46] Preskom S. (2005) Pharmacokinetics and therapeutics of acute intramuscular ziprasidone. Clin Pharmacokinet 44:1117-33.

[47] NDA20-825. (2000) Clinical Pharmacology and Biopharmaceutics Review.

[48] Miao Y, Chen G, Ren L, Pingkai O. (2016) Preparation and evaluation of ziprasidone-phospholipid complex from sustained-release pellet formulation with enhanced bioavailability and no food effect. J Pharm Pharmacol. 68(2):185-94.

[49] Dening T., Rao S., Thomas N., Prestidge C. (2016) Silica encapsulated lipid-based drug delivery systems for reducing the $5 \mathrm{fed} /$ fasted variations of ziprasidone in vitro. European Journal of Pharmaceutics and Biopharmaceutics 1-10.

[50] Setthacheewakul S, Mahattanadul S, Phadoongsombut N, Pichayakorn W, Wiwattanapatapee R. (2010) Development and evaluation of self-microemulsifying liquid and pellet formulations of curcumin and absorption studies in rats. Eur $\mathrm{J}$ Pharm Biopharm. 76: 475-85. 
[51] Marghade S, Musmade P., Moorkoth S. (2012) HighPerformance Liquid Chromatographic Assay for Ziprasidone in Plasma Samples: Application to Pharmacokinetic Studies in Rats. Journal of Chromatographic Science 50:902-908.

[52] Zakowiecki D, Cal K, Kaminski K, Adrjanowicz K, Swinder L, Kaminska E, (2015) The Improvement of the Dissolution Rate of Ziprasidone Free Base from Solid Oral Formulations. AAPS PharmSciTech 20(4):1-12.

[53] Hamelin B, Allard S, Laplante L, Miceli J, Wilner K, Tremblay J. (1998) The effect of timing of a standard meal on the pharmacokinetics and pharmacodynamics of the novel atypical antipsychotic agent ziprasidone. Pharmacotherapy. 18(1):9-15.

[54] Nagwa G., Amira Y. (2011) Synthesis of some oxindole derivatives as potential antipsychotic and anticonvulsant agents. International journal of pharmacy and pharmaceutical sciences. 3(3):213-219.

[55] Kaminski K, Adrjanowicz K, Wojnarowska Z, Grzybowska K, Hawelek L, Paluch M. (2011) Molecular dynamics of the cryomilled base and hydrochloride ziprasidones by means of dielectric spectroscopy. J Pharm Sci. 100(7):2642-57.

[56] Newa M, Bhandari K, Li D. (2007) Preparation, characterization and in vivo evaluation of ibuprofen binary solid dispersions with poloxamer 188. Int J Pharm 343:22837 .

[57] Miao Y, Chen G, Ren L, Ouyang P. (2016) Preparation and evaluation of ziprasidone-phospholipid complex from sustained-release pellet formulation with enhanced bioavailability and no food effect. J Pharm Pharmacol. 68(2):185-94.

[58] Hancock B, Parks M. (2000) What is the true solubility advantage for amorphous pharmaceuticals? Pharm Res. 17(4):397-404.

[59] Poluri K., Mulpur E., Puttugunta S., Govada K. (2013) Formulation development and evaluation of novel oral soluble films of ziprasidone hydrochloride in the treatment of schizophrenia, Int J Pharm Pharm Sci.5(2): 600-608.

[60] Hong, J., Shah, J., McGonagle, M. (2011) Effect of cyclodextrin derivation and amorphous state of complex on accelerated degradation of ziprasidone. J. Pharm. Sci. 100: 2703-2716.

[61] Kim, Y., Oksanen, D., Massefski J., Blake, J., Duffy, E., Chrunyk, B. (1998) Inclusion complexation of ziprasidone mesylate with beta-cyclodextrin sulfobutyl ether. J. Pharm. Sci. 87:1560-1567.

[62] Junghanns, J., Mueller, R. (2008) Nanocrystal technology, drug delivery and clinical applications. Int. J. Nanomed. 3:295-309.

[63] Miceli J, Glue P, Alderman J, Wilner K. (2007) The effect of food on the absorption of oral ziprasidone. Psychopharmacol Bull. 40(3):58-68. 38 .

[64] Pfizer. (2011) Zeldox ${ }^{\circledR}$ (ziprasidone hydrochloride) capsules 20, 40, 60, and $80 \mathrm{mg}$ - Product Monograph. Kirkland, Quebec, Canada. 